\title{
Sarlo o la taquigrafía de la cultura
}

Sarlo or Culture's Shorthand

Adriana Amante ${ }^{\mathrm{a}}$

DOI: https://doi.org/10.11144/Javeriana.cl24.sltc

Universidad de Buenos Aires, Argentina

amante@retina.ar

ORCID: https://orcid.org/0000-0001-5542-2081

\section{Resumen:}

Los múltiples saberes que sustentan la acción crítica de Sarlo no son necesariamente previos al abordaje, sino muchas veces consecuencia de lo que los objetos críticos que va diseñando le marcan como ineludibles. Este artículo se propone analizar algunos aspectos de su escritura: su capacidad de síntesis conceptual, el impulso aforístico, el manejo de la economía de un texto en función del medio en el que se inserta y el modo taquigráfico de notación para la ideación crítica. Si con Barthes o con Benjamin aprendió a leer y con Schorske o Berman, a entrar y salir desprejuiciadamente de la literatura, con (y en) su propio libro La máquina cultural Sarlo aprendió a escribir. Se trata, aquí, de indagar el plan de operaciones de su obra ensayística y el modo en que adopta los gestos críticos que le fascinan de aquellos que lee en una inflexión original.

Palabras clave: crítica, ensayo, aforismo, plan, taquigrafía.

\begin{abstract}
:
The various expertises that support Sarlo's critical practice are not necessarily previous to her writing; on the contrary, they are usually the inevitable outcome defined by her critical objects. This article analyzes some of the aspects of Sarlo's writing: her capacity for conceptual synthesis, her aphoristic impulse, the adjustment of textual economy in accordance to the different media and the tachygraphic mode of her critical imagination. Just as she learned to read with Barthes or Benjamin, and just as she learned to get in and to get out of literature unprejudicedly with Schorske or Berman, with (and in) her own book La máquina cultural Sarlo learned to write. My purpose is to study the operational plan of her essayist work and the original inflection she develops in order to incorporate the critical gestures that fascinates her in the authors she reads.
\end{abstract}

Keywords: Critic, essay, aphorism, plan, tachygraphy.

Todos los buenos ensayistas son escritores. Beatriz Sarlo

\section{Vitruviana}

Después de Sarmiento, Beatriz Sarlo es la argentina que mejor encarna la concepción vitruviana de la cultura; o, más específicamente, de la cultura que debe tener quien ejerce su métier. Lo que en el siglo I a. C. Marco Vitruvio Polión indicaba como preceptiva para el arquitecto es legítimamente trasladable - propongoa lo que debe saber un crítico de la cultura para abordar sus objetos del modo más completo, creativo e interesante, ya que prescribe el conocimiento esmerado de diversas ciencias y artes como un requisito sine qua non del diestro ejercicio profesional. Así, "[c] onviene que [el arquitecto —o el crítico, refuerzo-] sea instruido, hábil en el dibujo, competente en geometría, lector atento de los filósofos, entendido en el arte de la música, documentado en medicina, ilustrado en jurisprudencia y perito en astrología y en los movimientos

Notas de autor

a Autora de correspondencia. Correo electrónico: amante@retina.ar 
del cosmos". E inmediatamente agrega (y se explaya sobre) la necesidad de saber también literatura, óptica, aritmética, historia (Vitruvio 6-9).

Junto con los saberes de la teoría literaria, de la retórica, de la historia de la literatura, del análisis discursivo o de la lingüística general, más previsibles en una persona formada en Letras, Sarlo va desplegando su interés por el cine, la fotografía, los videojuegos, la pintura, la arquitectura, el jazz, la política, la educación, el teatro, el urbanismo, que son universos ideológicos, estéticos y técnicos en los que se sumerge para entender e internalizar sus principios constructivos, sus procedimientos y herramientas de análisis, la historia de sus movimientos y sus protocolos. Y si antepuse a la acción crítica de Sarlo los saberes que la sustentan, no es porque sean necesariamente previos al abordaje, sino justamente porque son muchas veces consecuencia de lo que los objetos críticos que va diseñando le marcan como mandatos que se le vuelven pulsionalmente ineludibles. ${ }^{1}$

Sarlo no entra en los campos extraliterarios como una aristócrata que va a husmear lo que se usa o lo que se viene, sino como una obrera que está dispuesta a cargar con los deberes que todo aprendizaje —entendido casi como una misión - impone. Y no se trata del conocimiento como acumulación, claro, como bien lo señala ella misma al observar las "elecciones estratégicas en el cuerpo de la lengua francesa y otros pocos territorios" (me gusta esta palabra) que conforman el sistema Barthes, que es "arborescente pero nunca enciclopédico". No es la acumulación, sino el procedimiento lo que la imanta: "No es una cuestión de gusto, ni siquiera una cuestión de ideas, ni de estilo. Se trata, más bien, del descubrimiento de una sensibilidad y de sus reflejos, dónde pone los acentos, cuáles son los detalles que le importan" (Sarlo, "Barthesianos" 11). Así se planta en "Barthesianos de por vida”, texto de una sola página que es una declaración amorosa y al mismo tiempo un manifiesto, tanto del modo del ejercicio crítico en Sarlo como del desiderátum de la escritura académica si quiere ser creativa. La clave está en un adjetivo y un adverbio, que subrayo: "En 1958, Barthes inició un estudio sobre la moda. Todavía no había escrito una tesis de doctorado porque había pasado de un tema a otro sin alcanzar nunca ese género fatal de la disertación académica. Naturalmente, fue rechazado". Es cuestión de evitar lo fatal y de asumir las consecuencias ineludibles de las derivas, como hizo este escritor sindicado como "demasiado literario" porque, en efecto, "tomaba sus argumentos de la literatura o los convertía a la literatura, pasándolos por su albedrío o su capricho” (11). Y Sarlo también toma, más que los argumentos, los procedimientos de la literatura, para irradiar su pensamiento por fuera del campo restringido. Porque esa es también la función que le asigna al intelectual: aquel que puede interpretar lo social con las herramientas y las armas (que son formas ideológicas también) que le da su métier de base; pero proyectándose más allá de su —y voy a usar esa palabra que me gusta - territorio para analizar y al mismo tiempo intervenir con su interpretación sobre la cosa pública. ${ }^{2}$ Ese despliegue no está exento de estrategias, y por lo tanto puede materializarse como una de las formas dialécticas de la guerra, como la polémica o el debate. De ese modo, Sarlo asume como intelectual otra función que tal vez haya aprendido, no solo o no tanto en sus años de militancia política, sino más que nada en sus lecturas de Sarmiento o de Alberdi: la del publicista. Entendido el término según su uso decimonónico, es el letrado cuyas ideas, que atañen a los asuntos de interés público, se manifiestan y se difunden en los medios de prensa e intervienen así sobre lo social. ${ }^{3}$ Es por eso que Sarlo puede - y suele- leer la sociedad o la política con o a partir de los procedimientos aprendidos en el ejercicio de la crítica literaria, ámbito en el que ha cultivado sus destrezas con excelencia y eficacia, lo que puede volver sus artículos en la prensa escrita o sus participaciones en la televisión tan demoledores como irritantes.

[T2]Plan de operaciones

No debería llamar la atención, entonces, que a menudo Sarlo se refiera a las acciones de un crítico o a las de un escritor con la palabra "plan", que eleva a título de uno de sus libros cuando universaliza el que le dio a un artículo sobre El discurso amoroso - libro de Barthes que recoge los seminarios en la École des Hautes Études en Sciences Sociales, 1974-1976-: "Plan de operaciones para enamorados". Y como en la Argentina cualquier mención a un plan de operaciones no puede eludir las reminiscencias morenistas, el uso de la expresión revincula la literatura con su dimensión política. Por eso, tal vez sea mejor pensar que, más que los 
procedimientos, lo que Sarlo observa en el ejercicio de la crítica de la cultura de los otros son las operaciones, como se ve en sus consideraciones de Roland Barthes pero también de Carl Schorske.

Un plan es, “[e]n urbanismo, producto intelectual previo a una acción. Es un tecnicismo tomado de la arquitectura, en la que alude al hecho de formalizar un proyecto en una dimensión diferente de la de su materialización" (Novick 75). La voz del Diccionario de Arquitectura en la Argentina redactada por Alicia Novick recupera la naturaleza de origen de un término del que hace uso también la escritura, como la misma entrada lo demuestra al tomar en consideración la definición del Larousse de 1879: "El arte de escribir ha tomado el término plan de la arquitectura y lo utiliza para significar el conjunto de lineamientos que forman un primer diseño" (75). Pero si el plan es "guía de composición" que precede a la acción, cuando no ha sido diseñado de manera explícita puede recuperarse retrospectivamente a partir de los productos materiales de su ejecución, y esto vale tanto para recomponerlo cuando no se lo tiene como para evaluar su cumplimiento cuando ha sido formulado previamente. Yo no podría afirmar que Beatriz Sarlo haya tenido un plan claro y distinto al comienzo de su escritura crítica, y no digo enunciado, tal vez ni siquiera vislumbrado; pero creo que es posible ver el modo en que cierto plan de operaciones fue desplegándose sobre la base de algunas directrices que, como los planes directores del urbanismo, fueron haciendo que la crítica literaria argentina avanzara sobre nuevas zonas o territorios y propusiera nuevas modalidades para su práctica. ${ }^{4}$

Lo que Sarlo se planteaba como problema de la crítica en 1984, en "La crítica: entre la literatura y el público", terminó constituyendo su plan de operaciones porque, como suele suceder cuando ella señala una necesidad, se hizo cargo en primera persona y asumió el cambio que reclamaba, encarando el deseo que formulaba y las tareas que de algún modo prescribía: la de lograr una crítica (y ya no quiero decir literaria, porque en el sistema Sarlo ese adjetivo puede terminar resultando restrictivo) que pueda vincular las prácticas de la universidad con la de medios de comunicación más amplios; la de producir textos que no sean más enrevesados que sus objetos; ${ }^{5}$ la de devolverle a la forma ensayística la positividad que tenía antes de la década del sesenta sin que eso implique, no obstante, ni superficialidad ni impresionismo, y que a la vez pueda conservar la especificidad disciplinaria y conceptual que la puesta en crisis de los sesenta le hicieron ganar, para permitirse una relación comprometida pero a la vez lúdica y deseante con los objetos; y, en el plano de lo más evidente pero no necesariamente de lo más fácil de lograr, la de conseguir que la crítica se desembarace del amaneramiento del discurso que la había ido invadiendo progresivamente. No era, ciertamente, el periodismo cultural el que iba a poder ocupar el vacío de la crítica literaria, sino la crítica literaria salida de sus propios confines para extender el campo de lo cultural, y sería precisamente Sarlo una - si no la mayor - artífice de ese cambio, junto con la revista cultural más determinante de los años ochenta: Punto de Vista. ${ }^{6}$ En ese que deviene su plan de operaciones, Sarlo postula modelos que la crítica argentina, si reducida a un discurso marginal y jergoso o si recluida en el conformismo de las tradiciones ideológicas o discursivas, no podría nunca alcanzar: escribir/ pensar como Barthes, Benjamin o Auerbach.

$\mathrm{Si}$ "Barthesianos de por vida" es el manifiesto de la interpretación y de la escritura crítica, "Viena, dos ciudades" es el manifiesto sarleano del modo de leer, que adquiere la forma autobiográfica de una historia intelectual. Allí, Sarlo indaga el modo en que Schorske estudia una ciudad (o, mejor, estudia una cultura concentrándose en una ciudad) y exhibe su aprendizaje: "Schorske está poseído por el interés absorbente de su objeto. No se aburrió jamás estudiando Viena y este goce desborda el interés académico y hace posible una experiencia de intensidad subjetiva" (Sarlo, "Viena” 70). Encandilados por la fascinación que Fin-deSiècle Vienna les produjo, Sarlo y los contemporáneos que compartieron con ella la transición democrática y la vuelta de y a la polis, no se percataron de que el de Schorske no era un libro orgánico, sino una compilación de artículos; no obstante lo cual (y de ahí el efecto engañoso) no adolecía de "unidad de escritura", dado que esta radicaba en "un movimiento libre, ensayístico, que se traslada de las citas al texto, que a su modo lo 'contagian"” (elogia en particular el hecho de que "sus fuentes tienen casi siempre belleza e inteligencia literaria") (Sarlo, "Viena" 70-71). Sarlo recoge en plural lo que le dejó Schorske como un aprendizaje vivido colectivamente por los que lo leyeron y difundieron en los ochenta, aunque probablemente sea ella la cautiva 
principal de ese embeleso; deslumbramiento que se tradujo en una especie de militancia de difusión que desde Punto de Vista o desde las clases de Literatura Argentina II de la Facultad de Filosofía y Letras de la Universidad de Buenos Aires (UBA) (cuyos receptores no siempre coinciden o se solapan, como se sabe) apuntalaba la creencia, esparciendo sus beneficios entre nuevos feligreses. ${ }^{8}$ El precipitado más inmediato es Una modernidad periférica: Buenos Aires 1920 y 1930, el libro de 1988 en el que Sarlo, ya no sintiéndose plena con el campo de aplicación de la crítica literaria o, mejor, con su modo de configurar y abordar los objetos, intenta otra cosa, arrebatada por la pasión lectora que le provocan tanto Fin-de-Siècle Vienna de Carl Schorske como All that is Solid Melts into Air de Marshall Berman:

Todo libro comienza como deseo de otro libro, como impulso de copia, de robo, de contradicción, como envidia y desmesurada confianza. En mi caso, hubo dos [...]. Se mezclaban, sin duda, con mis obsesiones anteriores más persistentes: Barthes, Williams o Benjamin. (Una modernidad 7)

¿Y qué toma de ellos? La forma "desprejuiciada con la que entraban y salían de la literatura”, cómo podían ver estética en textos que no eran literarios y política en textos que lo eran, porque abordaban sus materiales fuera de la trilla y, fundamentalmente, porque "los dos se proponían la reconstrucción de un mundo de experiencias a través de los textos de la cultura" (Sarlo, Una modernidad 7-8).9

El complemento de la lectura de Schorske está en la otra Viena, ciudad-objeto de otro abordaje, ya no desde la historia cultural, sino desde el ensayo filosófico: la Viena de Massimo Cacciari. Si la de Schorske fue decisiva para reencauzar el modo en que Sarlo seguiría ejerciendo la crítica como práctica cultural, la que le dejó Hombres póstumos de Cacciari tal vez haya sido una enseñanza de repercusión más íntima. Porque

Cacciari comienza su libro con un ensayo sobre la obra de Otto Wagner, la iglesia de San Leopoldo en el hospital psiquiátrico del Steinhof, desde donde se divisa toda la ciudad. Su primera proposición, a diferencia de Schorske que cree posible leer una sociedad y una cultura en todos sus objetos, es que San Leopoldo tiene mucho de indescifrable: no puede decirse lo que expresa ni lo que anuncia. (Sarlo, "Viena” 76)

No es la primera vez que Cacciari, y más precisamente su descripción de la iglesia de San Leopoldo con los vitrales de Kolo Moser están en el foco de la consideración de Sarlo. En "Del otro lado del horizonte", artículo sobre la escritura ensayística que había aparecido en diciembre de 2001, la toma como ejemplo de condensación (una idea no completamente desplegada; una síntesis que, sin explicar el modo, lo orienta) y analiza cómo al encabezar el libro de Cacciari establece su perspectiva de lectura y de sentido; ${ }^{10}$ cosa que evidentemente Sarlo no solo registró muy bien, sino que internalizó hasta el punto de señalarle el principio (el incipit, pero también la razón) de su propio libro Viajes. De la Amazonia a las Malvinas, de 2014. Voy a escandir el texto de apertura con los períodos de esa perspectiva:

La iglesia de San Leopoldo, desde que llegué a Viena, había sido mi obsesión. [...] Tenía un plano con los edificios modernistas y ese había sido mi único itinerario. Ya los conocía antes de llegar y entonces los observé como quien regresa, no como quien llega por primera vez. En 1992, un libro, Viena fin de siglo de Carl Schorske, me había convertido en una especie de falsa experta, que simulaba bastante bien un saber sobre la ciudad de las primeras décadas del siglo XX [...]. ${ }^{11}$

Simulaba una familiaridad tan convincente que la dueña de la pensión donde vivía me preguntó si todos los argentinos conocían Viena con ese detalle. El caso puede anotarse como extrema devoción o, si se quiere, enfermedad cosmopolita.

[...] [E]n una ficha de cartón llevaba escrito el comienzo de un ensayo de Cacciari: "Dos caminos simétricos, en las laderas de la floresta vienesa, dan acceso a la iglesia de San Leopoldo. La iglesia de Wagner, coronando el complejo hospital para enfermos mentales de la ciudad de Viena, surge del tupido bosque con su refulgente cúpula de cobre dorado. Nadie podría decir lo que esta obra anticipa, al igual que sería difícil afirmar lo que expresa”. O sea que esa tarde de sábado, siguiendo a Cacciari, yo quedé absorta frente a una obra que pedía justamente no ser interpretada. Dispuesta a llevar esta experiencia hasta donde fuera posible. [...]

Había llegado a Viena para hacer una especie de performance de lo que sabía sobre la ciudad. Actuaba fingiendo que reconocía todo, que todo me resultaba familiar porque antes lo había visto en los libros. (11-14).

Casi como el anillo de Moebius de "Continuidad de los parques", Sarlo pasa de una cara a la otra, de la lectura a la experiencia personal, del discurso al cuerpo, sin solución de continuidad: todo está previsto como 
si estuviera escrito, porque está escrito. O, como el Alberdi extasiado en su viaje a Suiza por la topografía sentimental de Julie y Saint-Preux en La Nouvelle Héloïse; o, como la Emma Bovary que marcaba con el dedo en el mapa los itinerarios obligados por el Tout-Paris, Sarlo realiza lo que ha leído, confirmando la naturaleza cultural del paisaje: no se trata solo del espacio en sí mismo, configurado a partir de lo que in situ impacta a los sentidos, a las emociones y a la capacidad de conocimiento, sino también a partir de todo lo que se sabe, lo que se oyó, se intuyó y fantaseó antes y fuera de ese lugar, que es en definitiva lo que ha predispuesto a la viajera a desearlo y valorarlo: porque la ha puesto "en disponibilidad" (Viajes 13, 16).

Pero, contra toda planificación, Sarlo se vio ganada por la irrupción de lo inesperado (aunque justamente ese estar "en disponibilidad", absolutamente concentrada en el objeto del deseo, fue lo que hizo posible que emergiera). Ese desvío estuvo, en su caso, marcado por los pasos sigilosos de alguien que venía midiendo los suyos cuando salió de la iglesia, a corta pero suficiente distancia, para terminar apoyándole la mano sobre el hombro, desde atrás, y luego retirarse tan silencioso como se había mantenido hasta ahí. La viajera, que planifica los itinerarios y las acciones de sus viajes con la misma minuciosidad con que investiga cuestiones parciales para integrarlas a una red de ideas, se entrega al "salto de programa" que constituye la esencia del viaje de aprendizaje: el momento en que, como el loco del psiquiátrico de Steinhof, algo escapa a la lógica de la previsibilidad y puede permanecer inescrutable para siempre, como la iglesia de San Leopoldo de Viena de Otto Wagner, que es ya la iglesia de San Leopoldo de la Viena de Cacciari, que es ya la iglesia de San Leopoldo de la Viena de Sarlo. ${ }^{12}$

\section{Pedagogía de la écfrasis}

Si con Barthes o con Benjamin aprendió a leer y con Schorske o Berman aprendió a ejercer de otro modo la crítica, con (y en) su propio libro La máquina cultural Sarlo aprendió a escribir. Porque, sin dejar de hacer lo que venía haciendo, en 1998, con ese libro, ensaya otra vez algo nuevo pero ya no tanto o, en rigor, no solo en relación con el modo de abordar los objetos, sino realizando una torsión discursiva, que en este caso es ante todo narrativa (aunque no exclusivamente). La máquina cultural. Maestras, traductores y vanguardistas es un momento bisagra, de quiebre y cambio en la escritura de Sarlo, quizás su salto de programa estilístico, como si toda la vida hubiera estado preparándose para eso - para decirlo parafraseando otra anécdota famosa, en este caso de Borges-, como si todos sus textos anteriores la hubieran ido poniendo "en disponibilidad". Porque en ese libro experimenta para transformarse. Sarlo, que para la fecha ya ocupaba como crítica un lugar que le permitía hablar desde el yo, decide asumir otro riesgo: el riesgo de decir "yo", pero no como ella sino como otra. En el primer episodio del libro - "Cabezas rapadas y cintas argentinas"-, le da la primera persona del singular a la maestra Rosa del Río, y conserva el yo que remite a su propia persona en las notas al pie, donde la investigadora Sarlo despliega sus fundamentos, su erudición y su solidez y, como en algunas novelas o poemas del siglo XIX — como José Mármol de Carlos (el protagonista de sus Cantos del Peregrino), por caso—, habla de su criatura en tercera persona. ${ }^{13}$

"Estaba tan claro el carácter autoritario del episodio [...], que se me ocurrió tomar la voz y la perspectiva de la maestra para ver si se entendía algo más que una equivocación insensata y desbordante de ideología" (Sarlo, La máquina 277). Sarlo se esmera en argumentar —en el texto que, aunque colocado al final del libro y con su mismo título, podría funcionar como prólogo - algo que de todas maneras podía entenderse — como ella esperaba - sin que fuera explicitado: que su operación no era la del etnógrafo que narra una historia de vida con la ilusión de transparencia en la reproducción de la experiencia ajena. No es el personaje, sino su discurso, el material sobre el que se opera: "Frase a frase he sido completamente fiel a lo que ella decía. Pero lo que ella decía fue mi material, el material del relato que yo he cortado y compuesto con su voz" (La máquina 278). ${ }^{14}$ Tampoco los testimonios que constituyen la base del episodio final son historias de vida. "La noche de las cámaras despiertas" actúa por composición de un relato que busca reponer, antes que sus asuntos, los planos de 
los seis o siete films de vanguardia que varios cineastas filmaron en una sola noche y cuyas copias se perdieron en la fugacidad de la intervención política, en los ardides para ganarle a la censura y en las desprolijidades del tiempo. La materialidad discursiva vuelve a estar en el foco del interés de la narradora que, sin encarnar como protagonista ni como testigo, se propone contar a través de una narración-patrón que, más que por discursos o acciones, pretendía estar constituida por los planos que se afanaba por recomponer: lo formal por sobre lo temático, que es donde anidaba lo político de esa experiencia vanguardista. ${ }^{15}$

Un deseo de recuperar las imágenes perdidas se repite, pero en primera persona, en el libro de viajes. La foto está en la base del recuerdo de toda experiencia, que a la distancia no podrá retener lo real, pero podrá seguir aferrada para siempre a su representación:

Las fotografías se abrieron en la pantalla de la computadora, imprevistas como meteoritos que llegaban de otro espacio y de otro tiempo. Me las enviaba Alberto Sato, que las había digitalizado para que no terminaran fundidas en un borroneado sepia, que ya estaba avanzando sobre los colores antes nítidos de las diapositivas Ferrania. (Sarlo, Viajes 115)

El archivo de la memoria de uno es el otro. En este caso, el archivo de la memoria de la viajera es Alberto Sato. Por su prolija conservación de lo que ella pierde o nunca tuvo sin lamentarse demasiado: apuntes en libretas de viaje, croquis tomados al natural como tan bien los saben hacer los pintores o los arquitectos viajeros, fotografías ordenadas que se han transportado incluso en la errancia del exilio. ${ }^{16}$ En el libro de viajes de Sarlo, las imágenes fotográficas que se conservan se suceden para articularse, no como continuidad, sino como corte. ${ }^{17}$ Pueden operar como condensación y como elipsis, que son dos de los recursos que le adjudica al ensayo: la condensación, como vimos con el ejemplo que ella misma da de lo insondable en la descripción de la iglesia de San Leopoldo de Cacciari, puede ser leída "como una descripción de un espacio o como una perspectiva cultural" (Sarlo, "Del otro lado" 28); y la elipsis, como un derecho del ensayo a prescindir de sus nexos de articulación y no como una condena del género como en la ficción. Solidaria con la idea del montaje como conflicto de Eisenstein, el corte - y no el encadenamiento- es la característica principal de la cultura para Sarlo. $^{18}$

Pero hay una materialidad en la que los recuerdos del arquitecto y de la literata se solapan, y los de uno pueden encontrarse con los del otro en el territorio común del discurso, del despliegue verbal:

Uno de nosotros, el que parecía un "hijo del país", llevaba su libreta de notas, donde también dibujaba los planos sencillísimos de las casas y las iglesias coloniales. Al atardecer, sentado en el suelo, abría la libreta y nosotros nos alejábamos. [...] Casi medio siglo después se las pido para reconstruir este viaje y unas páginas escaneadas aterrizan en mi computadora. Tienen la sencillez y la precisión de quien sabe que lo que describe está siendo descripto por primera vez por extranjeros (somos todos argentinos, pero extranjeros en la puna) desde la conquista española. También tienen la cautela de quien escribe por primera vez. $(\text { Sarlo, Viajes } 78)^{19}$

En la morosa delectación por el detalle del Sato de Sarlo hay algo de la del Saer de Sarlo: una pedagogía de la écfrasis; porque no sería impensable que ese escriba ajeno al territorio de la escritura literaria -el arquitecto - haya proporcionado un modelo para poner ante los ojos, por medio de la palabra, lo que se sustrae a la vista, permitiendo contravenir el fatum de que las palabras pueden "cite but never sight", en la certera expresión dada por W. J. T. Mitchell en Picture theory (152). Así es como Sarlo se solaza en la transcripción de la certera imagen que Alberto Sato diseña por escrito de los trulli, un tipo especial de vivienda que el salto de programa les regala en la Puna jujeña:

De aspecto similar a los hornos de pan, se erguían las viviendas de los mineros, realizadas en piedra con techos de lajas que formaban una cúpula perfecta. Para acceder a su interior hay que agacharse y trasponer una abertura estrecha, sin puertas ni rastros de que en algún momento haya existido. Un dintel de piedra sostiene el arranque de la cúpula. El recinto es cuadrangular, sin ventanas, de escasos 4 metros cuadrados, con una altura de aproximadamente dos metros y medio. (Viajes $78-79)^{20}$ 
La cautela prodiga una notación precisa y concentrada, rasgos que Sarlo detecta en el haiku, esa pasión que comparten - para la misma fecha, aunque sin vinculación- Barthes y Saer. "Tuvo razón Barthes al señalar que el haiku ofrece una historia que la ficción puede desarrollar” (Zona Saer 42); y también:

Saer expande el haiku hasta que se expande como descripción. Pero del haiku conserva el valor del detalle preciso que es poético. Sin precisión no hay haiku. Tampoco hay descripción saeriana. Como simple ejercicio, se puede convertir en haiku una descripción-acción. (Zona Saer 44$)^{21}$

Y vuelvo a Eisenstein para recordar que, para él, los haikus -esos "bosquejos impresionistas concentrados"- podían ser pensados como "frases de montaje", como "listas de tomas" (36).

Esa concentración es una forma de la sintaxis, que no está lejos de la que se da en la escritura ensayística de la propia Sarlo, y que se manifiesta en por lo menos cuatro aspectos: la capacidad de síntesis conceptual, el impulso aforístico, el manejo de la economía de un texto en función del medio en el que se inserta y el modo taquigráfico de notación para la ideación crítica. Voy a analizarlos en algunos textos que me parecen ejemplares.

\section{Tanto con tan poco}

En Escritos sobre literatura argentina, se recopila con el título de "Tanto con tan poco" un artículo que Beatriz Sarlo había publicado en el suplemento "Cultura y Nación” del diario Clarín en 1993 como Severa Villafañe. A esos textos publicados en periódicos Sarlo los considera una escritura pautada por la aceleración de los medios periodísticos. Ella escribe tanto esos textos urgentes como los otros, no pautados por una exterioridad, sino por las necesidades de su objeto o de su proyecto estético; y sabe cómo diseñar las estructuras de derivación en un caso y en otro, tanto como sabe dar en el tono justo de acuerdo con las circunstancias y medios de publicación. Así, prescindirá sin pesadumbre de la nota al pie en los textos de periódicos, pero también podrá convertirla en un juego de estilo en La pasión y la excepción, que es donde Sarlo más ha avanzado en el uso y la conceptualización de ese recurso, configurándolo directa y explícitamente como hipotexto al poner en acto su más interesante forma compositiva: no la del entrecortado período que abruma tantas veces al lector que ve minada la fluidez del texto que lo absorbe (importunándolo, en el mejor de los casos al pie, cuando no forzándolo a moverse hacia el final del texto) para ofrecerle tantas veces solo una —aun si necesaria - finalmente mísera referencia bibliográfica, sino la de la articulación entre comprobación, bibliografía e ideas, que puede convertir las notas al pie en pequeñas iluminaciones. ${ }^{22}$

Recordemos que Sarlo ha podido ver que la urgencia en el estilo de Sarmiento no era una determinación del medio exterior, como suele considerarse, sino una característica constitutiva y a la vez una coartada:

Su inestabilidad no es causada solo por el apuro con que se despachan textos que serán publicados en la prensa, como el Facundo. Es un rasgo interno. La escritura rápida que exige el periodismo le viene bien, porque se adecua a una velocidad subjetiva. ("Sarmiento" 4)

Si le fuera externa a su estilo, podría pensarse que la "aceleración que le imponen a la escritura" los periódicos la lleva a Sarlo a la práctica de la síntesis, que domina con soltura, elegancia y seguridad. Pero - como ella misma vio en el caso de Sarmiento - tal vez sea su capacidad de síntesis conceptual la que encuentra tanto en la aceleración como en el acotado espacio de las páginas del periódico un lugar que le resulta tan apropiado como natural. Sarlo sabe entrar al sistema de un proyecto estético, de un texto, de un autor, con la certeza de que debe extraer de él lo fundamental, para convertirlo en el núcleo de significación que podrá analizar de manera concentrada pero nunca críptica, yendo a lo esencial para obtener lo indispensable, que será entonces la cifra del proyecto, del texto o del autor. 
Como dijimos, del periódico al libro, el título del artículo va del nombre de la heroína de la pequeña historia que Sarmiento condensa espléndidamente en el capítulo X de Facundo ("Severa Villafañe"), a la caracterización magistral de un estilo, el de Sarmiento, que Sarlo conoce como nadie ("Tanto con tan poco"):

Se trata solo de un párrafo. Sin embargo, en esa brevísima ficción histórica, Sarmiento escribe un argumento de novela de aventuras, de novela romántica, de folletín. El Facundo tiene decenas de cuadros como el de la Severa Villafañe: el día que Facundo maltrata a su padre, cuando pelea a lanzazos con un oficial, cuando se resiste a pagar las deudas de juego, cuando aterroriza a sus prisioneros. Pero nunca como en el párrafo que dedica a la historia de Severa, Sarmiento consigue tanto con $\tan$ poco. $(23)$

En el incipit de este artículo están toda la fuerza y la revelación, tanto del objeto de análisis (ya no solo del episodio focalizado de la Severa, sino de la escritura del Facundo en general) como de la escritura crítica, que condensa también en un solo párrafo el modo en que selecciona una gema de entre las que abundan en el libro de Sarmiento, que deja ver la serie sobre la que Sarlo la recorta para singularizarla, y que va directo al objeto, porque, en pos de la solidez de su hipótesis, sabrá prescindir de cualquier desvío y de toda sobreabundancia de información. En ese solo párrafo del texto de Sarlo se percibe el universo literario en el que se mueve Sarmiento para dar forma a este breve episodio, se da una primera caracterización del temible Quiroga, se hace notar la potencia de una escritura que es abordada como materialidad discursiva y no solo como asunto ideológico explicitado, y se juega la fuerte apuesta de la escritura crítica que sabe que en lo taxativo o terminante (que no es lo mismo que en lo arbitrario o lo terco) se tramitan algunas formas de la eficacia. ${ }^{23}$

Sarlo no sucumbe a la tentación de la cita como una condena o un pecado inevitables de la crítica literaria. Y, en vez de poner el párrafo feliz de Sarmiento para que se lo lea de manera directa y termine hablando por ella, se da el gusto de reescribirlo, dándole rienda suelta al deseo propio de su escritura:

Rechazado cien veces, Facundo intenta envenenar a Severa; luego, en un paroxismo de pasión, toma opio para quitarse la vida. Una tarde entra al patio de la casa familiar y arrebata a Severa, que se le resiste; Facundo la humilla, la golpea hasta desangrarla, pero no puede tomarla.

Después, Severa Villafañe se esconde en un convento, confiando en que este obstáculo, opuesto a la pasión por la religión, sería al mismo tiempo su cárcel definitiva y su refugio. Hasta allí llega Facundo, obliga a que se le abran las puertas y que Severa se presente. Ella lo ve, da un grito y cae. (“Tanto con tan poco” 23-24)

Sarlo entabla, así, una medición de fuerzas con el original, que —al ser escamoteado- se vuelve más deseado, gracias precisamente a la luz que ella ha echado sobre él y al que honra con un sistema que articula equilibradamente la glosa con la interpretación, las hipótesis con la voluntad de estilo. ${ }^{24}$

Ya lo sabemos: Sarlo capta bien los planes de obra y entiende el proceso de la escritura sarmientina; por eso puede afirmar con lucidez que ese párrafo, "[s]intético como un plan de trabajo futuro, es al mismo tiempo, una condensación de géneros literarios y un juicio moral" (23). Texto que, pudiendo escribirse de manera desplegada, Sarmiento concentra en el fulgurante coto de ese párrafo que - por suerte - no tendrá reescritura y que encontrará en su eventual provisoriedad su forma más acabada (la definitiva, pero también la perfecta).

"Sintético como un plan de trabajo futuro". Es en esa frase inspiradamente certera que puede apreciarse tanto la captación que Sarlo tiene de su objeto como el modo en que funciona su propia escritura. La síntesis en Sarlo no radica solo en su capacidad para manejarse con los períodos, los espacios o los tiempos pautados de la intervención escrita o televisiva; algunas de sus ideas tienen, incluso, el precipitado del aforismo: luminosidad que se enciende y concluye sin enamorarse de su propio hallazgo como para caer en la tentación de alargamiento; no solo por ejercicio de discreción o de austeridad, sino también porque sabe que el efecto de esa idea opera por reverberación o como un afterimage (el mismo efecto que Sarmiento pretendía haber conseguido con su Facundo), cuyo centelleo impacta más en la memoria de quien lee si no se machaca demasiado sobre su valor. Sarlo sostiene que los aforismos son "ensayos que todavía no fueron escritos más allá de la frase" ("Del otro lado" 18), y en el estilo de indagación que ella misma practica esa propuesta se convierte en sustancia. Muchos de sus ensayos podrían ser escandidos siguiendo la serie de aforismos diseminados, 
que van formando una cadena de derivación argumentada. En ellos se ve el modo en que operan sus síntesis conceptuales:

"El ensayista no dice lo que ya sabe, sino que hace (muestra) lo que va sabiendo, sobre todo indica lo que todavía no sabe" /
"En el ensayo se dibuja un movimiento más que un lugar alcanzado" / "El plan del ensayo debe ser descubierto en sus restos,
siempre dispersos a lo largo de un texto que a veces oculta su plan y a veces lo muestra sin cumplirlo" / "Una forma del ensayo
es la pregunta y su desenlace no necesariamente ofrece una respuesta, sino una nueva pregunta, bordeando lo que no se sabe,
que se ha ampliado como resultado en negativo [...]" / "Así como no se resume en sus partes, un ensayo no se resume en sus
hipótesis" / "[L]a ley del ensayo es no someterse a programa, ni siquiera al que definen sus promesas". ("Del otro lado" 16-18)

La obligación que tiene el aforismo - en su origen hipocrático- de ser memorable no es un presupuesto necesario en la escritura de Sarlo, pero se recupera por sus efectos. Y si, como propone Alain Montandon, el pensamiento aforístico rehúye toda sujeción a lo habitual, a lo tradicional, a lo convencional o a lo prejuicioso, su forma exploratoria - agrego yo- lo instala en una relación natural con la forma ensayística. Y es paradójico que dentro de sus pautas formales de composición el aforismo se mantenga abierto y libre, cuando - por definición etimológica- es una demarcación de límites, lo que hace que anide en él la apariencia de una clausura que es de todos modos siempre huidiza como un horizonte, como sostiene Maurice Blanchot (en Montandon 74). Idea que puede religarse con la pulsión que mueve, para Sarlo, la novela de Proust y que podría funcionarle como modelo: "Escribir para encontrar", aspirando a asir las cosas que están "del otro lado del horizonte", a la deriva entre el deseo y lo inapresable ("Del otro lado" 16). ${ }^{25}$ Sintético como un plan de trabajo futuro, el aforismo también consigue lo que el párrafo de Sarmiento: tanto con tan poco.

[T2] La sintaxis de un estilo

Sarlo sabe bien que la esencia del aforismo como inquieta indagación no debe ser confundida con la certeza llana y resolutiva del slogan publicitario, como se ve en "La taquigrafía de la política”, artículo también breve de 1999. El poder de la síntesis, aquí, está en la naturaleza ideogramática de las frases de la política que analiza: son "ideas que se vuelven materiales, visibles" y, en ese sentido, el "volveré y seré millones, [que] dicen que dijo Eva Perón” (98) es el non plus ultra del repertorio nacional. Como con las pequeñas historias del Facundo entre las que se distinguía la de la Severa Villafañe, como con los más de cien libros que ha investigado para el episodio de los rapaditos, Sarlo da el precipitado ordenado de lo que pesquisa a través de la síntesis conceptual que de ello deduce, dejando marcas que indican por dónde ha pasado. Así es como prolija, ordenada, exhaustiva, en el primer párrafo entrega la lista:

Compatriotas, correligionarios, descamisados, hermanos, amigos, camaradas, compañeros: palabras con las que la política ha convocado durante un siglo. Vendepatrias, oligarcas, fascistas, comunistas, chupacirios, galeritas, flor de ceibo, negros de mierda, imberbes, burócratas, yanquis, bichos colorados: formas del insulto político. Con estas palabras se puede componer un vocabulario histórico. Tuvieron la fortuna de ser pronunciadas por millones que rápidamente se identificaron con ellas o las repudiaron. Son la taquigrafía de la política. Suenan como una nota musical que encierra un tema completo. ("La taquigrafía" $99)^{26}$

A partir de ahí, podrá concluir que, lejos de esos insights que no fueron producto de la estrategia de ningún asesor de imagen, la política actual fatiga la sintaxis breve de sus frases descartables y, entre la televisión y la comunicación publicitaria, no alcanza a ver que quizás “esté necesitando párrafos más extensos” (100).

Como el término "plan", el de "taquigrafía” y sus derivados también son recurrentes y — propongosumamente productivos en el estilo crítico de Sarlo. Del acertado movimiento analítico que se pone en juego en este texto, me interesa sobre todo su propio modo taquigráfico de funcionamiento (esto es: no solo el del discurso político argentino, sino también el de la política de la escritura de Sarlo). La aceleración impuesta por la escritura en periódicos que ya mencionamos encuentra su recurso más indicado en esa grafía rápida de la taquigrafía: una notación sintética que capta al vuelo la matriz o lo esencial del pensamiento, especialmente útil para la deriva ensayística que se da su forma sabiendo que se publicará en la prensa. 
Y tal vez la taquigrafía sea el complemento notacional del aforismo que, como la estructura de un edificio - como Sarlo pensó en relación con Adorno-, va urdiendo su argumento sobre la base de los fundamentos que lo sostienen. A la vez, la taquigrafía comparte con el croquis o el boceto el trazo acelerado y la exclusión del detalle, aunque aquella sea el precipitado de una voz que se persigue, para captarla al ritmo que se enuncia (esa voz puede ser externa, pero también la del propio pensamiento); y este último, "el plan de trabajo futuro", género de lo transitorio, vicario por anticipación y no conclusivo. ${ }^{27}$ Son precisamente el de taquigrafía y el de boceto los conceptos que le permiten enunciar a Sarlo la más feliz síntesis del sistema de la obra de Victoria Ocampo, que incluye materiales y acciones tan diversamente amplios como la serie de testimonios, la creación de una revista cultural, su papel de gestora cultural y de mediadora entre lenguas y geografías, o la importación de novedades literarias, pero también estéticas, de diseño y de arquitectura:

Victoria Ocampo misma había proyectado una casa moderna en Mar del Plata, y había contratado a un constructor de galpones para realizarla. De manera casi salvaje, manda hacer una casa cúbica, es decir el esquema de una casa moderna. No es una casa refinada ni se origina en la intervención estética de un arquitecto, sino el gesto taquigráfico de la casa moderna realizado por una aficionada. Gesto rápido, como de quien hace un boceto. (La máquina 179; subrayado en el original)

El proyecto de la casa de Mar del Plata es un esquema; el de la calle Rufino de Elizalde, una imitación. En ambos casos, de todas maneras, Ocampo hace, a mano alzada, sus propios planos (sus propios planes). Sarlo ve esos dos proyectos como formas de traducir "a un lenguaje moderado la arquitectura modernista radical" ( $L a$ máquina 185): la más abstracta del esquema y la más programática de la imitación; y considera tanto las casas de Ocampo como la revista Sur como máquinas de traducir, lo que puede ponerse en sintonía interesante con la postulación de Le Corbusier de la casa como máquina para vivir o habitar; la pintura como máquina para conmover, de Ozenfant; o el libro como máquina para leer, de Valéry. ${ }^{28}$

La idea del "gesto taquigráfico" enunciada en "Victoria Ocampo o el amor de la cita", que es un verdadero hallazgo, se vuelve cifra perfecta y envidiable del modo en que funciona el sistema crítico completo de Sarlo. Más allá de los espesores materiales de los objetos que aborda (textos literarios, ciudades, planes, discursos, imágenes fijas o en movimiento), lo que ella lee son los gestos: ${ }^{29}$ los ademanes y protocolos de los sistemas culturales para cuyo abordaje se vale de procedimientos que, si aprehendidos inicialmente en la crítica literaria, Sarlo supo hacerlos desbordar de sus límites, produciendo un salto de programa determinante para la cultura argentina y generando así una sintaxis diferente, una nueva ars combinatoria para la indagación intelectual.

\section{Referencias}

Altamirano, Carlos y Beatriz Sarlo. "Una vida ejemplar: la estrategia de Recuerdos de provincia”. Literatura/Sociedad, Hachette, 1983, pp. 174-180.

Boyer, M. Christine. Le Corbusier, Homme de Lettres. Princeton Architectural Press, 2011.

Eisenstein, Sergei. "El principio cinematográfico y el ideograma”. La forma del cine, Siglo XXI, 1986.

Filippelli, Rafael. "La ciudad y el cine”. El plano justo. Cine moderno: de Ozu a Godard, editado por Rafael Filippelli y David Oubiña, Santiago Arcos-Bafici, 2008, pp. 17-39.

Giordano, Alberto. "La crítica de la crítica y el recurso al ensayo". Modos del ensayo. De Borges a Piglia, Beatriz Viterbo, 2005, pp. 249-260.

Luppi, Juan Pablo. "Una ausente presencia bajo el arte de narrar. Revisiones de la política en la fidelidad crítica saeriana (1986-2011)”. Exlibris, n. ${ }^{\circ}$ 4, 2015, pp. 75-89.

Martínez Gramuglia, Pablo, Martín Servelli e Inés de Mendonça. "El gaucho malo de la prensa". Historia crítica de la literatura argentina, editado por Adriana Amante, vol. 4, Emecé, 2012, pp. 259-291.

Mitchell, W. J. Picture theory. University of Chicago Press, 1994.

Montandon, Alain. Les formes brèves. Hachette, 1992. 
Novick, Alicia. "Plan". Diccionario de Arquitectura en la Argentina. Estilos, obras, biografias, instituciones, ciudades. Editado por Francisco Liernur y Fernando Aliata, tomo 4, Clarín, 2004, pp.75-86.

Podlubne, Judith. "El pensamiento de la crítica (Beatriz Sarlo y Horacio González)". Boletín / 6 del Centro de Estudios de Teoria y Critica Literaria, octubre de 1998, pp. 99-115.

Sarlo, Beatriz. "Barthesianos de por vida". Plan de operaciones. Sobre Borges, Benjamin, Barthes y Sontag. Ediciones Universidad Diego Portales, 2013, p. 11. Publicado originalmente en Página/12 en el 2005.

Sarlo, Beatriz. Borges, un escritor en las orillas. Ariel, 1995.

Sarlo, Beatriz. "Del otro lado del horizonte". Boletín / 9 del Centro de Estudios de Teoría y Crítica Literaria, diciembre de 2001, pp. 16-31.

Sarlo, Beatriz. Escenas de la vida posmoderna. Intelectuales, arte y videocultura en la Argentina. Ariel, 1994.

Sarlo, Beatriz. Juan Maria Gutiérrez: historiador y critico de nuestra literatura. Editorial Escuela, 1967.

Sarlo, Beatriz. La ciudad vista. Mercancias y cultura urbana. Siglo XXI, 2009.

Sarlo, Beatriz. "La crítica: entre la literatura y el público". Espacios, n. ${ }^{\circ}$, diciembre de 1984, pp. 6-11.

Sarlo, Beatriz. "La escuela en crisis". Tiempo presente. Notas sobre el cambio de una cultura. Siglo XXI, 2001, pp. 101-110.

Sarlo, Beatriz. La máquina cultural. Maestras, traductores y vanguardistas. Ariel, 1998.

Sarlo, Beatriz. La pasión y la excepción. Siglo XXI, 2003.

Sarlo, Beatriz. "La taquigrafía de la política". Tiempo presente. Notas sobre el cambio de una cultura. Siglo XXI, 2001, pp. 99-100.

Sarlo, Beatriz. "Plan de operaciones para enamorados". Plan de operaciones. Sobre Borges, Benjamin, Barthes y Sontag. Ediciones Universidad Diego Portales, 2013.

Sarlo, Beatriz. "Sarmiento. El escritor inestable". Suplemento "Cultura", Perfil, 6 de noviembre de 2011, p. 4.

Sarlo, Beatriz. "Tanto con tan poco". Escritos sobre literatura argentina. Siglo XXI, 2007, pp. 23-24.

Sarlo, Beatriz. Una modernidad periférica: Buenos Aires 1920 y 1930. Nueva visión, 1988.

Sarlo, Beatriz. Viajes. De la Amazonia a las Malvinas. Seix Barral, 2014.

Sarlo, Beatriz. "Viena, dos ciudades". Plan de operaciones. Sobre Borges, Benjamin, Barthes y Sontag. Ediciones Universidad Diego Portales, 2013, pp. 67-77. Publicado por primera vez en 2012, en el Boletín bibliográfico electrónico.

Sarlo, Beatriz. Zona Saer. Universidad Diego Portales, 2016.

Sato, Alberto. "Rutas históricas en la puna jujeña". Autoclub. Revista del Automóvil Club Argentino, n. ${ }^{\circ}$ 55, noviembrediciembre de 1970), pp. 62-65.

Schorske, Carl. "La idea de ciudad en el pensamiento europeo: de Voltaire a Spengler". Punto de Vista, traducido por Segunda Epigonalli, n. ${ }^{\circ} 30$, julio-octubre de 1987, pp. i-xvii, https://www.bazaramericano.com/media/punto/ coleccion/revistasPDF/30.pdf.

Vitruvio Polión, Marco. “La arquitectura y los arquitectos”. Los diebz libros de Arquitectura. Traducido por José Luis Oliver Domingo, libro 1, 1997, pp. 26-33.

\section{Notas}

1 Para un abordaje más teórico sobre esa "intersección de saberes", que la propia Sarlo "identifica como provenientes de la historia intelectual”, y la superación del campo restringido de los saberes especializados y académicos, véase Podlubne (101-102).

2 De entre las varias oportunidades en las que Sarlo reflexiona sobre la función del intelectual, véase el capítulo V, "Intelectuales", de Escenas de la vida posmoderna. Intelectuales, arte y videocultura en la Argentina .

3 Sobre Sarmiento como publicista en particular, $c f$. Martínez Gramuglia, Pablo, Martín Servelli e Inés de Mendonça.

4 Ya no puede leerse como mera casualidad que en su primer libro Sarlo haya estudiado la obra del primer crítico e historiador de la literatura nacional, Juan María Gutiérrez, que "representa en la literatura argentina la primera toma de 
conciencia, a través de la cual se contempla un proceso, se evalúa una producción, se crea una teoría y se estudian sus antecedentes" ( Juan Maria Gutiérrez 9).

5 Una cuestión compleja requiere de una explicación también compleja; porque, caso contrario, corre el riesgo de convertirse en lo que ya no es (lo que no quiere decir en modo alguno que deba ser enrevesada, ni estar reñida con la pulsión didáctica), ha dicho también Sarlo alguna vez frente a las demandas simplificadoras de la televisión, en una respuesta que sigue de algún modo la matriz de la famosa anécdota sobre Albert Einstein intentando explicarle a una señora burguesa la teoría de la relatividad hasta que, a fuerza de simplificar, para cuando la señora logró entenderla, de esa teoría compleja ya no quedaba nada.

6 En esa intervención, Sarlo amplía el campo de la literatura (argentina) como objeto hasta el de la "textualidad” (argentina) para abarcar producciones que, no siendo literarias per se, podían ser abordadas productivamente por el ensayo crítico. Con el tiempo, terminaría ampliando el concepto de textualidad a objetos no necesariamente verbales, para entender como Barthes y como Benjamin que otras materialidades podían ser leídas como textos. Alberto Giordano (253) tiene una mirada más crítica sobre este artículo de Sarlo que yo: considera que Sarlo ve el ensayo como confinado en su instrumentalidad retórica; yo creo que es en esa consideración de la retórica del ensayo por parte de Sarlo donde se asienta tanto lo político como la moral de la práctica.

7 Y, dentro de lo que Sarlo aprende a leer leyendo a Schorske, algo fundamental: "Schorske hace las operaciones que todavía hoy haríamos para estudiar una ciudad” (72). Por eso no le cuesta apuntar sintéticamente el libro que —hipótesis contrafáctica de Sarlo- Schorske habría podido escribir tan sólidamente como el que en efecto escribió si hubiera tomado un desvío poniendo como objeto lo que dejó afuera.

8 Las lecturas no entran en sus artículos solo como un medio de adquisición de datos, claro, sino como hitos que van articulando la formación de un grupo; y su recuento no está puesto al servicio de una reflexión autorreferente, sino que conforma el núcleo de significación de una estructura de sentimiento. Esos momentos de concentración iluminadora se convierten, más que en la deriva de una historia de vida, en los mojones que articulan la historia cultural argentina (aunque quizás debería decir fundamentalmente de Buenos Aires) de los últimos cuarenta años.

9 Es interesante ver cómo Sarlo va de Borges, un escritor en las orillas, de 1993, a La ciudad vista, de 2009. Si en el libro sobre Borges analiza cómo la imaginación urbana de la literatura diseña distintas configuraciones de ciudades, en La ciudad vista invierte el gesto y repiensa el sistema de Borges a partir de la ciudad. O sea: va del análisis de la ciudad que delinea el sistema literario de Borges (cifrada en el ideologema de la orilla, y también en la captación de ese leve anacronismo entre la ciudad que Borges construye en su literatura y la que le es contemporánea) a la indagación de cómo funciona el sistema Borges pensado desde la teoría de la ciudad. En el primer caso, el centro es Borges; en el segundo, lo urbano. A la contundente influencia de Schorske en Sarlo habría que agregar una red de reflexiones compartidas que fue urdiendo con Adrián Gorelik, Graciela Silvestri y Jorge F. Liernur en el espacio de Punto de Vista, donde ellos han desplegado sus saberes especializados sobre arquitectura y urbanismo también en un campo ampliado; y las de Rafael Filippelli, que por fuera de sus películas sobre Buenos Aires- encuentran su manifestación más certera en su texto "La ciudad y el cine", donde analiza la relación entre la autonomía del cine y la ciudad real como una ¿paradoja? de la representación.

10 "Del otro lado del horizonte" es celebrado por Alberto Giordano porque considera el ensayo como forma (Giordano 253).

11 Fue antes de 1992; Sarlo equivoca aquí el año: el libro de Schorske había sido publicado en diciembre de 1980, ella lo lee en 1985 (como bien recuerda en "Viena, dos ciudades" (69), y como puede comprobarse por lo influyente que resultó en Una modernidad periférica, que es del 88) y a partir de entonces lo difunde sistemáticamente en sus clases de literatura argentina de la UBA. En el número 30 de Punto de Vista, de julio-octubre de 1987, se incluye como separata la traducción de otro texto de Schorske, "The Idea of the City in European Thought: Voltaire to Splenger", realizada por Segunda Epigonalli, la evidente Beatriz Sarlo que se escondía bajo un nombre de fantasía casi tan puerilmente manifiesto como el del Baltasar Espinosa de "El evangelio según Marcos” de Borges que, cuando cambia su hábitat citadino por el campo abierto, empieza por ignorarlo todo para terminar identificando con naturalidad el canto del jilguero, al que la viajera Sarlo por momentos se parece, sobre todo cuando rememora a esa niña que vacacionaba en Deán Funes y aprendía de don Lajos Kovacic o de Don Ángel Naveira las cosas del campo como si salieran de una novela (que está bastante en sintonía con el Don Segundo Sombra de Ricardo Güiraldes que la propia Sarlo enseñaba y sobre el que el cuento de Borges ironiza), pero que eran de la vida real: "Distinguía una gallina bataraza de una leghorn y conocía el pelo de los caballos" y aprendió cómo "no cansar un caballo sin necesidad, a no galopar por galopar, a no castigar el animal ni azuzarlo" (Viajes 58, 64).

12 Una de las experiencias de clase más determinantes que yo tuve fue aquella de 1986 en la que Sarlo, apoyada con una relajada seguridad en el escritorio del aula magna de la Facultad de Filosofía y Letras de la UBA, todavía en la calle Charcas, en plena disertación sobre Don Segundo Sombra de Güiraldes, afirmó con límpida certeza: "En el capítulo XIII, el texto se pone loco". En ese momento supe lo que yo misma había ido a buscar allí, aunque me demorara una vida conseguirlo: yo quería poder decir, algún día, de un texto - de cualquier texto- algo semejante. No se trataba de remedar su contenido. Ya ni siquiera podría recordar qué decía ella que pasaba en ese capítulo como para que un texto tan ortodoxo, de gauchos de plástico, como leíamos en la bibliografía que la propia Sarlo nos proporcionaba, pudiera — por ventura- salirse de 
quicio. Quería (sigo queriendo) poder remedar su gesto crítico. Ese salto de programa por parte de Sarlo se convertiría en el mío.

13 "He consultado más de cien libros de lectura de esa época" (La máquina 77), afirma en la primera nota al pie, y nadie dudaría de esa abundancia: es la laboriosidad que se naturaliza y se pone de manifiesto, no como relato épico del acceso al saber, sino como presupuesto inexcusable del deber del crítico. Porque esa contundencia en el tono es la misma que puede indicar, por el contrario, la reticencia o el menoscabo, que en Sarlo es también una marca de franqueza, ética y medida justa: ¿cuánto hay que leer o es suficiente leer o analizar para poder deducir, afirmar e interpretar con solvencia y voz autorizada?, ¿cuál es el límite que puede ponérsele a la exhaustividad? Respecto de Victoria Ocampo, dice: "Incluso es probable que haya citado más poetas ingleses que franceses, aunque no he hecho la cuenta” (La máquina 118), "por lo que vi, la educación de la niña rica consistía..." (La máquina 121). En sus Viajes, donde la viajera opta en ocasiones por afectar una primera del plural (que opera con un efecto de tercera) que la distancie de la pulsión impúdica del yo, también despliega su erudición en las notas al pie muchas veces bajo la forma de una carta personal que le envía un interlocutor con quien ha estado departiendo sobre las cuestiones que le interesan para su texto y opta en varios casos por transcribir completa la carta (probablemente el mail) de su informante como una forma de dar una prueba del saber, pero también del reconocimiento del mérito del especialista. Así, entran los análisis de Alicia Bernasconi, Fernando Devoto, Roberto Di Stefano, Gastón Burucúa (aunque, en este caso, en el cuerpo central del texto), y fundamentalmente — pero con otras implicancias sobre las que me detendré más adelante- de Alberto Sato.

14 La maestra que un día decide raparles las cabezas a sus alumnos para sacarles los piojos, dice Sarlo, no es excepcional, “es una maestra del montón que cometió un solo acto fuera de quicio (en el sentido literal)" (La máquina 279). Otra vez, el salto fuera de programa, pero en este caso no bajo la forma de lo inesperado, sino bajo la forma de la desmesura, de la exageración de la medida, porque llevó al paroxismo el deber que la institución escolar en la que se insertaba le demandaba.

15 En La máquina cultural, Sarlo encuentra el andar o el gozo de cierta forma de la narración, aunque, más allá de cierto núcleo que podría constituir la peripecia, lo que hay sobre todo es una deriva que le debe al ensayo su modo analítico y reflexivo: así, el episodio de los rapaditos en la escuela pública o la larga y mítica noche de la performance cinematográfica de vanguardia y política son acciones que, sin dejar de reponerse en el texto y por el texto (y esto es lo que las convierte en acontecimientos: el hecho de poder engarzarlas en una cadena de sentido), se moldean como ideología.

16 Sarlo informa que Alberto Sato se llevaría consigo las fotografías tomadas en los viajes latinoamericanos que compartieron "porque con ellos me voy a ganar la vida", como en efecto sucedería al convertirse en historiador de la arquitectura en Venezuela (Viajes 266).

17 Hay que tener en cuenta que las fotografías que integran el archivo que se conforma en el libro propiamente dicho (y que no se reproducen) no son abundantes, pero se multiplican en las que se dejan ver en la página de internet de Pinterest de PlanetadeLibros Argentina.

18 Es la idea de base que propone en "La escuela en crisis", un artículo sobre la educación que recoge intervenciones de 1993, 1996 y 1998, incluido en Tiempo presente. Notas sobre el cambio de una cultura, de 2001, y que sigue vigente porque lamentablemente los problemas que allí se exponen todavía no han sido resueltos (la falta de ideales que la escuela pueda transmitir, la injusta distribución de oportunidades, la crisis de la alfabetización). Si Sarlo no desconoce las bondades de las destrezas adquiridas por los jóvenes en los medios masivos de comunicación o en la videocultura, cree de todos modos que no son suficientes para el desarrollo de habilidades "indispensables en el mundo del trabajo y de la política”: "La argumentación, el discurrir lingüistico, la escritura". Y la idea más importante: que la adquisición de una cultura "supone una serie de procesos de corte y no simplemente de continuidad respecto de lo cotidiano. Se aprende lo que no se sabe" (Sarlo, "La escuela" 102-103; resaltado en el original). Ese corte, que no debe ser ejercido como autoritarismo, es la garantía de las posibilidades de superación de los estudiantes y el freno antidemagógico que debe reclamarse ante una escolaridad ganada por la adulación del adolescente.

19 No solo las de la Puna, también le mandará las notas sobre Brasilia: "Son los recuerdos de un estudiante de arquitectura y, quizás por eso, difieran de los tuyos. Esos encuentros y desencuentros de la memoria siempre me resultan interesantes" (Viajes 243), le dice Sato en la carta que Sarlo incluye completa en una nota al pie.

20 El texto de Alberto Sato que ella cita se titula "Rutas históricas en la puna jujeña".

21 Para un análisis sistemático de los abordajes de la obra de Saer por parte de Sarlo anteriores a Zona Saer, cf. el artículo de Juan Pablo Luppi de 2015 para la revista Exlibris.

22 Véanse, por ejemplo, "Otra lectura de 'Evita Perón”, "El cuerpo del rey", "Vituperio", "Anacronismo”, "Disfraces", en La pasión y la excepción.

23 "Otra forma del ensayo es la afirmación radical, cuya radicalidad, precisamente, desencaja los pasos argumentativos" (Sarlo, "Del otro lado" 17).

24 Otra afirmación tan sintética como taxativa, que despliega enseguida su fundamento: "En lo que Sarmiento no cuenta está todo el folletín: la huida de Severa, las persecuciones, otros hombres que probablemente la amaban y que pudieron haber muerto para defenderla, la impotencia de sus hermanos, la exasperación de una casa donde ha entrado la sombra de algo 
inevitable" ("Tanto con tan poco" 24). Este solo fragmento, azuzado por el movimiento mismo de una prosa galopante que remeda el ritmo que ha captado en el texto del propio Sarmiento ("La historia de Severa es todo movimiento" [Sarlo, “Tanto con tan poco" 24]), podría confirmar que, en efecto, "el ensayo se piensa mientras se escribe" (Sarlo, "Del otro lado" 17).

25 Es sintomático que Sarlo, al referirse a la forma aforística que adopta la escritura ensayística de Adorno, la compare con la veduta holandesa: una verdad en perspectiva lejana, pero justa ("Del otro lado" 27-28).

26 Este fragmento eleva la ficha (ese instrumento técnico de la lectura analítica) al rango de la conceptualización. Como el plan o como el guion, aunque usualmente menos glamoroso y condenado a permanecer fuera de la escena, la ficha es un abordaje en primera instancia que está destinado a extinguirse en la consumación misma de su razón de ser: tiene el imperativo de convertirse en otra cosa, para la que justamente ha sido originado. Pero, como venimos siguiendo, hay planes (o - como se verá enseguida - también planos) de trabajo futuro que se convierten en textos definitivos y es precisamente en la fijación de lo transitorio donde radica su valor. El arte de la ficha también pudo haberlo aprendido Sarlo de Barthes.

27 Dice Le Corbusier: "El plan reclama la más activa imaginación. Reclama la más severa disciplina también. El plan es lo que determina todo, es el momento decisivo. El plan no es una cosa bonita a ser dibujada, como el rostro de la Madonna; es una austera abstracción" (Vers une architecture, citado por Boyer 307).

28 Para ahondar en la naturaleza de esas máquinas, $c f$. Boyer (299-305). No olvidemos que es el propio libro de Sarlo en el que se incluye el artículo sobre Victoria Ocampo el que hace de la idea de máquina su núcleo conceptual, como se explicita en "La máquina cultural", ese texto de cierre que funciona como clave y programa: "Este libro intentó mostrar el funcionamiento de una máquina cultural, que produjo ideas, prácticas, configuraciones de la experiencia, instituciones, argumentos y personajes" (273). Es significativo, por otra parte, que ya en 1980, en un artículo indispensable para los estudios sobre el autor de Facundo, Sarlo y Altamirano se hayan referido a "la máquina de aprender [mencionada asimismo como 'máquina de conocimiento'] que ha ideado Sarmiento", donde la cadena de los libros "que excluye al maestro y enlaza texto con texto, obras que se remiten unas a otras" es un elemento fundamental; y también a la "máquina de traducir", para aludir tanto al traslado concreto de una lengua a otra como a la adaptación al medio americano de todo lo leído; y lo más interesante: que la palabra venga del propio Sarmiento, cuando habla —en Recuerdos de provincia, que es el texto objeto central del análisis- de la "máquina sencilla de aprender idiomas" que resultó la enseñanza del latín recibida del clérigo Oro (Altamirano y Sarlo 184-187, 189). El artículo "Una vida ejemplar: la estrategia de Recuerdos de provincia”, de Sarlo y Altamirano, se publicó por primera vez en el n. 9 de Escritura en la edición de enero-junio de 1980.

29 La formación crítica también consiste, creo, más que en la imitación de los contenidos, en la adopción de los gestos de los críticos que nos gustan.

\section{Licencia Creative Commons CC BY 4.0}

Cómo citar: Amante, Adriana. "Sarlo o la taquigrafía de la cultura". Cuadernos de Literatura, vol. 24, n. ${ }^{\text {47, }}$ 2020. https://doi.org/10.11144/Javeriana.cl24.sltc 